\title{
HOW TO CALCULATE THE VOLUMES OF PARTIALLY FULL
}

\section{TANKS}

\author{
Antonio Valiente Barderas ${ }^{1}$, B.S.Stephania Gómez Rodea ${ }^{2}$ \\ ${ }^{1,2}$ Department of Chemical Engineering, Faculty of Chemistry.UNAM, C.U.México D.F. \\ Tel-56223764 \\ faty_avb@yahoo.com
}

\begin{abstract}
In the industry it is very common to find tanks, in many different shapes, totally or partially filled with a fluid. Some geometric shapes allow the calculation of volumes easily, other not so much. What complicates the matter is the fact that some tanks are in a horizontal position other in a vertical.Besides, most tanks are fitted with caps or heads of different shapes as the hemispherical, semi-elliptical or torispherical caps. To calculate the fluid volume in a vertical or horizontal tank can be complicated depending of the fluid height and the caps. This article makes a synthesis of the calculations for the volumes of most tanks and caps found in the industry and presents some examples.
\end{abstract}

Keywords: Tanks, Heads, Volume, Calculations.

\section{INTRODUCTION}

There are numerous types of containers used in industrial plants or processes. Some of these are designed to store substances for any process, this type of vessels are called, generally, tanks. In the industry, it is very common to find many different tanks filled totally or partially with a fluid. Some geometric shapes allow the calculation of volumes easily, other not so much. In this presentation a synthesis of the calculations is made to obtain volumes of tanks found in the majority of the industry, in addition we present calculations that exemplify the calculations.

\section{CALCULATIONS OF VOLUMES}

It is easy to calculate the volumes of tanks completely filled. However it is not so when they are partially filled. [3]

\subsection{Cylindrical Tanks}

The majority of tanks used in the chemical industry are cylindrical tanks, either in horizontal or vertical configuration.

Consider, for example, a cylindrical tank with length $\mathrm{L}$ and radius $R$, filling up to a height $H$. If you want to obtain the volume of the liquid that partially fills the tank, you should indicate if the tank is in horizontal or vertical position.

If the tank is placed upright, the volume of the liquid in the tank would be:

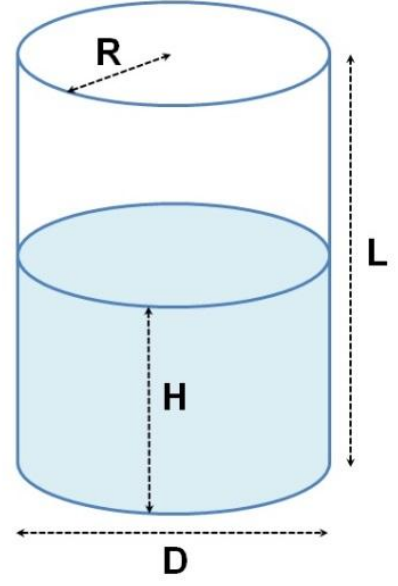

Fig 1. Vertical cylinder

$V=\pi R^{2} H=\frac{\pi}{4} D^{2} H$

If the tank is in a horizontal position, then there is a not so an easy variation of the volume with the height:

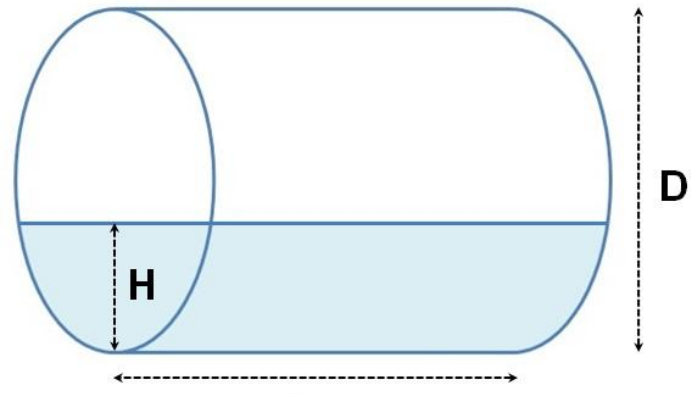

L

Fig 2. Horizontal cylinder 
Therefore, you must calculate the area of the liquid segment filling and multiplied it by the length of the tank.

Starting from analytic geometry:

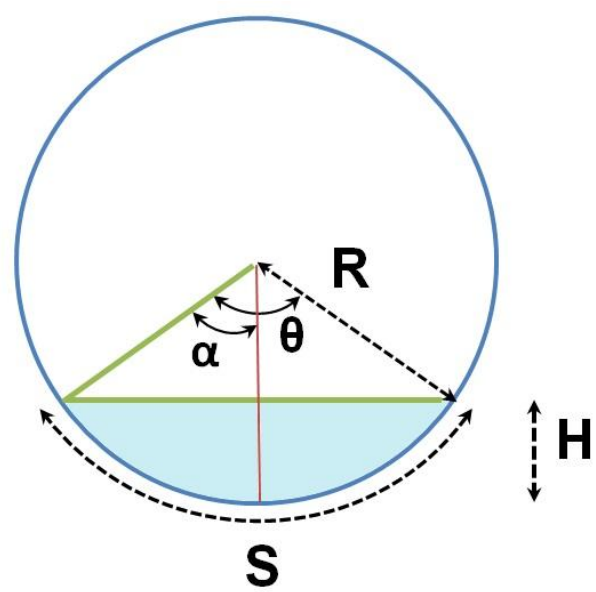

Fig 3. Areas and segments

Segment area $=$ Area of sector - triangle area

Sector Area $=\frac{1}{2} S R=\frac{1}{2} R^{2} \theta$

Table 1. Volume of a partially filled horizontal cylinders. (Source: Perry, "Handbook of chemical engineering",Sixth Edition. Mexico, 2001)[2]

\begin{tabular}{|c|c|c|c|c|c|c|c|}
\hline \multicolumn{8}{|c|}{ Edition. Mexico, 2001)[2] } \\
\hline H/D & $\begin{array}{l}\text { Volume } \\
\text { fraction }\end{array}$ & H/D & $\begin{array}{l}\text { Volume } \\
\text { fraction }\end{array}$ & H/D & $\begin{array}{l}\text { Volume } \\
\text { fraction }\end{array}$ & H/D & $\begin{array}{l}\text { Volume } \\
\text { fraction }\end{array}$ \\
\hline 0.01 & 0.00169 & 0.26 & 0.20660 & 0.51 & 0.51273 & 0.76 & 0.81545 \\
\hline 0.02 & 0.00477 & 0.27 & 0.21784 & 0.52 & 0.52546 & 0.77 & 0.82625 \\
\hline 0.03 & 0.00874 & 0.28 & 0.22921 & 0.53 & 0.53818 & 0.78 & 0.83688 \\
\hline 0.04 & 0.01342 & 0.29 & 0.24070 & 0.54 & 0.55088 & 0.79 & 0.84734 \\
\hline 0.05 & 0.01869 & 0.30 & 0.25231 & 0.55 & 0.56356 & 0.80 & 0.85762 \\
\hline 0.06 & 0.02450 & 0.31 & 0.26348 & 0.56 & 0.57621 & 0.81 & 0.86771 \\
\hline 0.07 & 0.03077 & 0.32 & 0.27587 & 0.57 & 0.58884 & 0.82 & 0.87760 \\
\hline 0.08 & 0.03748 & 0.33 & 0.28779 & 0.58 & 0.60142 & 0.83 & 0.88727 \\
\hline 0.09 & 0.04458 & 0.34 & 0.29981 & 0.59 & 0.61397 & 0.84 & 0.89673 \\
\hline 0.10 & 0.05204 & 0.35 & 0.31192 & 0.60 & 0.62647 & 0.85 & 0.90594 \\
\hline 0.11 & 0.05985 & 0.36 & 0.32410 & 0.61 & 0.63892 & 0.86 & 0.91491 \\
\hline 0.12 & 0.06797 & 0.37 & 0.33636 & 0.62 & 0.65131 & 0.87 & 0.92361 \\
\hline 0.13 & 0.07639 & 0.38 & 0.34869 & 0.63 & 0.66364 & 0.88 & 0.93203 \\
\hline 0.14 & 0.08509 & 0.39 & 0.36108 & 0.64 & 0.67590 & 0.89 & 0.94015 \\
\hline 0.15 & 0.09406 & 0.40 & 0.37353 & 0.65 & 0.68808 & 0.90 & 0.94796 \\
\hline 0.16 & 0.10327 & 0.41 & 0.38603 & 0.66 & 0.70019 & 0.91 & 0.95542 \\
\hline 0.17 & 0.11273 & 0.42 & 0.39858 & 0.67 & 0.71221 & 0.92 & 0.96252 \\
\hline 0.18 & 0.12240 & 0.43 & 0.41116 & 0.68 & 0.72413 & 0.93 & 0.96923 \\
\hline 0.19 & 0.13229 & 0.44 & 0.42379 & 0.69 & 0.73652 & 0.94 & 0.97550 \\
\hline 0.20 & 0.14238 & 0.45 & 0.43644 & 0.70 & 0.74769 & 0.95 & 0.98131 \\
\hline 0.21 & 0.15266 & 0.46 & 0.44912 & 0.71 & 0.75930 & 0.96 & 0.98658 \\
\hline 0.22 & 0.16312 & 0.47 & 0.46182 & 0.72 & 0.77079 & 0.97 & 0.99126 \\
\hline 0.23 & 0.17375 & 0.48 & 0.47454 & 0.73 & 0.78216 & 0.98 & 0.99523 \\
\hline 0.24 & 0.18455 & 0.49 & 0.48727 & 0.74 & 0.79340 & 0.99 & 0.99831 \\
\hline 0.25 & 0.19550 & 0.50 & 0.50000 & 0.75 & 0.80450 & 1.00 & 1.00000 \\
\hline
\end{tabular}

Where: $\theta=\frac{S}{R}=2 \cos ^{-1}\left(\frac{R-H}{R}\right)$

Segment area $=\frac{1}{2} R^{2}(\theta-\operatorname{sen} \theta)=R^{2} \cos ^{-1}\left(\frac{R-H}{R}\right)-$

$(R-H) \sqrt{2 R H-H^{2}}$

Therefore, the volume of liquid will be:

$V p=L\left[R^{2} \cos ^{-1}\left(\frac{R-H}{R}\right)-(R-H) \sqrt{2 R H-H^{2}}\right]$

Where the cosine is given in radians.

You can also get the volume by using the formula:

$V p=L R^{2}\left[\frac{\alpha}{57.3}-(\operatorname{sen} \alpha \cdot \cos \alpha)\right]$

Where: $\alpha=\frac{\theta}{2}(7)$ and $\cos \alpha=1-\frac{H}{R}$

It is also customary, to get the volume using tables or graphs which presents H/D based on the \% of volume. 
Figure 1. Percentage of full volume against $H / R$ relationship

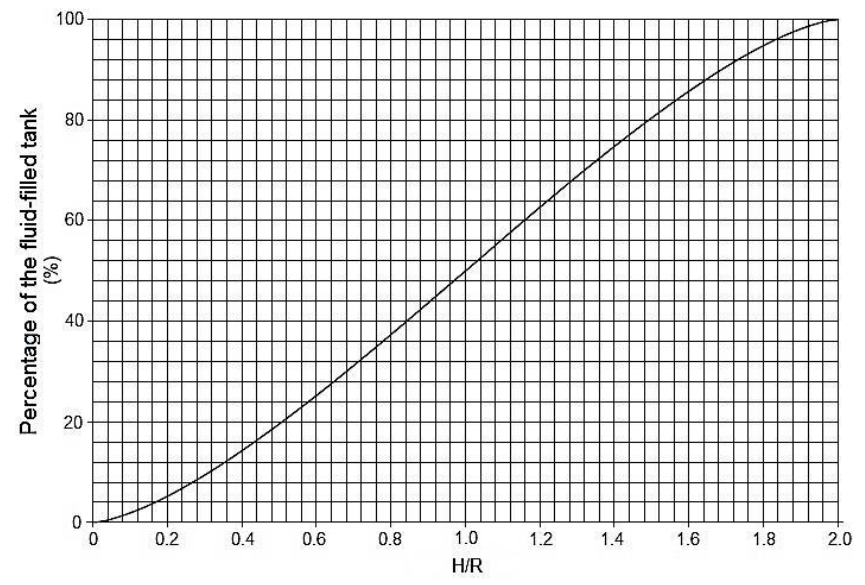

Graphic No.1.Percentage of volume in cylindrical tanks partially filled [2].

\section{Problem 1.}

Inan horizontal cylindrical tank with flat tops having the following dimensions:

$\mathrm{L}=7.62 \mathrm{~m}, \mathrm{D}=2.54 \mathrm{~m}, \mathrm{H}=0.762 \mathrm{~m}$

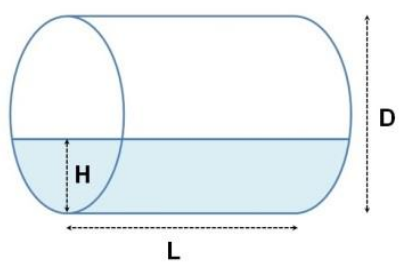

What is the volume of liquid contained in the tank?

$$
\begin{aligned}
& \frac{R-H}{R}=\frac{1.27-0.762}{1.27}=0.4 \\
& \cos ^{-1}(0.4)=66.42=1.159 \\
& V p=7.62\left[(1.27)^{2}(1.159)\right. \\
& -(1.27 \\
& \left.-0.762) \sqrt{2.54 \times 0.762-(0.762)^{2}}\right] \\
& =9.74 m^{3}
\end{aligned}
$$

Either,

$\cos \alpha=1-\frac{H}{R}=0.4$

$\alpha=66.42 ; \operatorname{sen} \alpha=0.9165$

$V p=7.62(1.27)^{2}\left[\left(\frac{66.42}{57.3}\right)-(0.9165 \times 0.4)\right]=9.74 m^{3}$

Also:

Total volume of the tank,

$V_{T}=0.785(2.54)^{2}(7.62)=38.59 m^{3}$

Percentage of the fluid-filled tank:
$\frac{H}{D}=\frac{0.762}{2.54}=0.3$

Using table 1 or graphic 1 , the percentage is 25 , therefore:

Vol $=0.25(38.59)=9.65 m^{3}$

\section{HEADS OR CAPS}

In the industry, the tanks are usually built with covers that are not flat. These caps or heads are, typically, of three types: 1)Hemispherical, 2)Semi-elliptical and 3) Torispherical. [7,8,4,1]

\subsection{Hemispherical Heads}

The depth ( $\mathrm{z}$ ) of this type of head is equivalent to the internal radius of the head or 0.5 of the internal diameter of the container. Hemispherical heads are used for higher pressures of design, for this reason they have the higher cost.

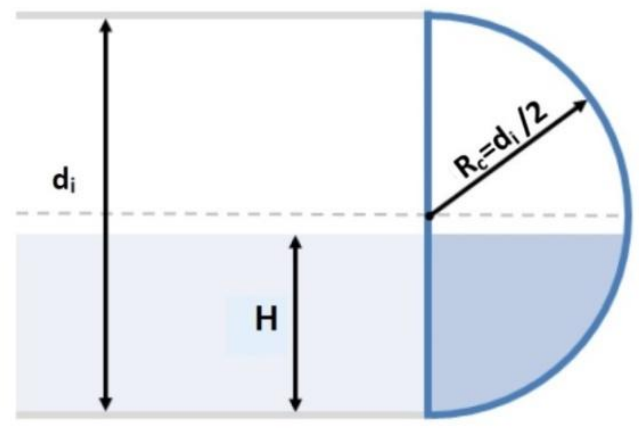

Fig 4. Tank with hemispherical head [9]

The total volume of the head is:

$V_{c}=\frac{2}{3} \pi R_{c}^{3}$

Where $\mathrm{Rc}$ is the inside crown radius,

$R_{c}=\frac{d_{i}}{2}$

The partial volume that occupies the fluid in the head $(\mathrm{Vp})$ is determined by:

$V_{p}=d_{i}^{3} C \frac{\pi}{12}\left[3\left(\frac{H}{d_{i}}\right)^{2}-2\left(\frac{H}{d_{i}}\right)^{3}\right]$

Where $\mathrm{C}$ it has a value of 1 according to the ASME code.

Problem 2.

In the previous problem, what would be the volume of the liquid contained in the tank if it has hemispherical caps?

In the previous problem: $\mathrm{Rc}=\mathrm{di} / 2=1.27 \mathrm{~m}, \mathrm{H}=0.762 \mathrm{~m}$, $\mathrm{di}=2.54 \mathrm{~m}$

Foranhorizontal cylinder without caps the volume of liquid is $9.74 \mathrm{~m}^{3}$ 
The partial volume of a head would be given by:

$$
\begin{aligned}
V_{p}=(2.54)^{3}(1) & \left(\frac{\pi}{12}\right)\left[3\left(\frac{0.762}{2.54}\right)^{2}-2\left(\frac{0.762}{2.54}\right)^{3}\right] \\
& =0.926 \mathrm{~m}^{3}
\end{aligned}
$$

Partial volume of two heads $=1.852 \mathrm{~m}^{3}$

Total volume $=1.852+9.74=11.59 \mathrm{~m}^{3}$

\subsection{Hemispherical Head in a Vertical Cylindrical}

Tank.

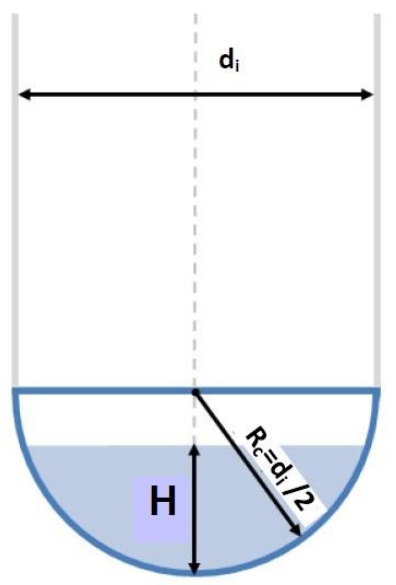

Fig 5. Hemispherical head in vertical tank [10]

Partial volume of fluid in the lower head,

$V_{p}=\frac{\pi}{6}\left(\frac{3}{C} d_{i} H^{2}-\frac{2}{C^{2}} H^{3}\right)$

Partial volume at the upper head,

$V_{p}=\frac{\pi}{12}\left(3 d_{i}^{2} H-\frac{4}{C^{2}} H^{3}\right)$

The depth (z) of this type of head is equivalent to 0.5 of the inner diameter and the constant $(\mathrm{C})$ has a value of 1 , in accordance with the ASME code.

The total volume of the head is given by equation (9):

$V_{c}=\frac{2}{3} \pi R_{c}^{3}$

\subsection{Semi-Elliptical Head in Horizontal Cylindrical}

\section{Tank.}

The depth of this type of head is lower than in the hemispherical head and higher than in the torispherical, therefore, the design pressures are those found between these two designs.

The most common semi-elliptical head is the ratio $2: 1$, whose depth $(\mathrm{z})$ is equal to one quarter of the diameter of the container, $1 / 4 \mathrm{di}$.

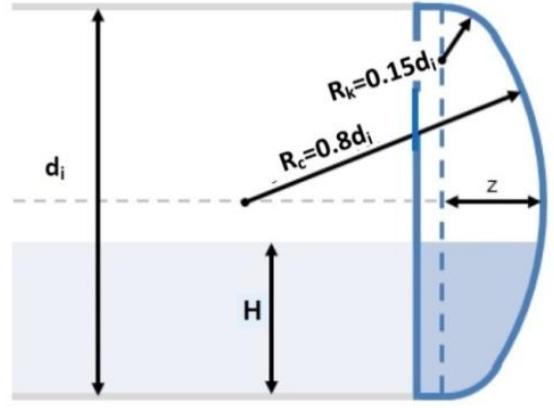

Fig 6. Semi-elliptical head in horizontal tank [9]

The partial volume of a liquid in a semi-elliptical cover is obtained with (11):

$V_{p}=d_{i}^{3} C \frac{\pi}{12}\left[3\left(\frac{h}{d_{i}}\right)^{2}-2\left(\frac{h}{d_{i}}\right)^{3}\right]$

The total volume of the head is:

$V_{c}=\frac{\pi d_{i}^{3}}{24}$

Where $\mathrm{C}$ it has value of $1 / 2$ according to ASME code.

\section{Problem 3.}

If in the problem 1 the tank have a semi-elliptical covers what will be the volume of liquid contained in the tank? For this tank:

$\mathrm{H}=0.762 ; \mathrm{L}=7.62 \mathrm{~m} ; \mathrm{di}=2.54 \mathrm{~m} ; \mathrm{C}=0.5$

$R c=0.8 d_{i}=2.032 m$

$R_{k}=0.15 d_{i}=0.381 m$

$$
z=0.25 d_{i}=0.635 m
$$

The partial volume of a head would be given by:

$$
\begin{aligned}
V_{p}=(2.54)^{3}(0.5) & \left(\frac{\pi}{12}\right)\left[3\left(\frac{0.762}{2.54}\right)^{2}-2\left(\frac{0.762}{2.54}\right)^{3}\right] \\
= & 0.463 \mathrm{~m}^{3}
\end{aligned}
$$

Partial Volume of two heads $=0.9266 \mathrm{~m}^{3}$

Total Volume $=0.9266+9.74=10.626 \mathrm{~m}^{3}$

\subsection{Semi-Elliptical Head on a Vertical Tank}

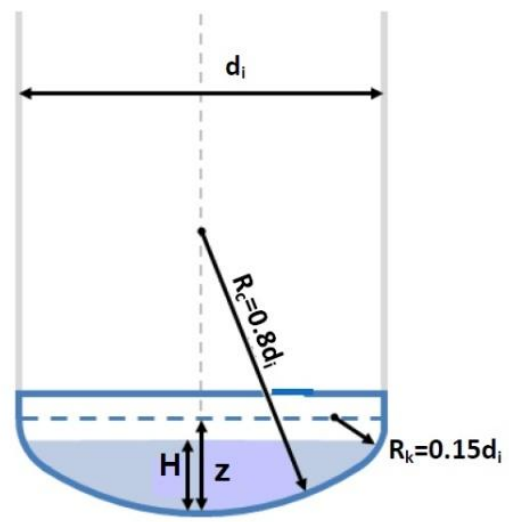

Fig 7. Semi-elliptical head in vertical tank [10] 
The partial volume of liquid in the bottom head is determined by (12),

$V_{p}=\frac{\pi}{6}\left(\frac{3}{C} d_{i} H^{2}-\frac{2}{C^{2}} H^{3}\right)$

And the partial volume at the upper head (13),

$V_{p}=\frac{\pi}{12}\left(3 d_{i}^{2} H-\frac{4}{C^{2}} H^{3}\right)$

The depth (z) of this type of head is equivalent to 0.25 of the inner diameter and the constant $(\mathrm{C})$ has a value of 0.5 according to the ASME code.

The total volume of the head is (14):

$V_{c}=\frac{\pi d_{i}^{3}}{24}$

\subsection{Torispherical Head In Horizontal Tank}

This is the more economical head and the most used in process vessels.

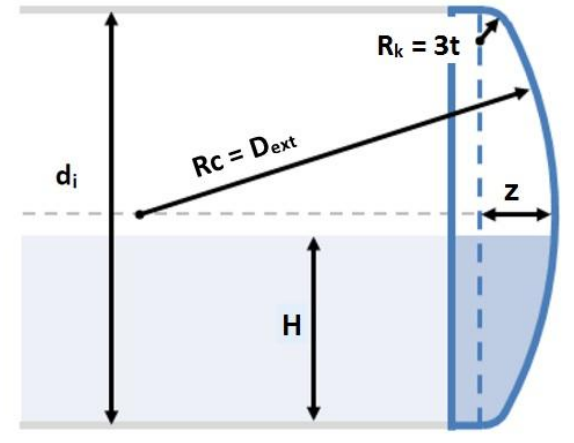

Fig 8. An horizontal tank with torispherical head [9]

The depth $(\mathrm{z})$ of these heads is given by the equation:

$z=R_{c}-\sqrt{\left(R_{c}-R_{k}\right)^{2}-\left(\frac{D_{e x t}}{2}-t-R_{k}\right)^{2}}$

Where:

$t=$ Thickness

$D_{\text {ext }}=$ External diameter $=d_{i}+t$

$R_{k}=$ Inside knuckle radius $=3 t$

$R c=$ Inside crown radius $=D_{\text {ext }}$

The calculation of the partial volume of liquid is also done with the equation (11):

$V_{p}=d_{i}^{3} C \frac{\pi}{12}\left[3\left(\frac{h}{d_{i}}\right)^{2}-2\left(\frac{h}{d_{i}}\right)^{3}\right]$

Where the constant $\mathrm{C}$ for heads with torispherical is calculated according to the ASME code by:
$C=0.30939+1.7197\left(\frac{R_{k}-0.06 D_{\text {ext }}}{d_{i}}\right)-0.16116\left(\frac{t}{D_{\text {ext }}}\right)+$

$0.98997\left(\frac{t}{D_{\text {ext }}}\right)^{2}$

The total volume of the head is determined by the following equation:

$$
V_{c}=0.9\left[\left(\frac{2 \pi R_{c}^{2}}{3}\right) z\right]
$$

Problem 4.

If the tank in problem 1 was fitted with torispherical heads and a thickness (t) of the material used of $1 \mathrm{~cm}$, what will be the volume of liquid contained in the tank?

Problem 1:

$\mathrm{L}=7.62 \mathrm{~m} ; \mathrm{H}=0.762 \mathrm{~m} ; \mathrm{di}=2.54 \mathrm{~m}$

$D_{\text {ext }}=d_{i}+t=2.55 \mathrm{~m}$

$R c=D_{\text {ext }}=2.55 \mathrm{~m}$

$R_{k}=3 t=0.03 m$

Head depth (z) is:

$z=2.55-\sqrt{(2.55-0.03)^{2}-\left(\frac{2.55}{2}-0.01-0.03\right)^{2}}$ $=0.3534 m$

While the constant $\mathrm{C}$ :

$$
\begin{array}{rl}
C=0.30939+1 & .7197\left(\frac{0.03-0.06(2.55)}{2.54}\right) \\
& -0.16116\left(\frac{0.01}{2.55}\right)+0.98997\left(\frac{0.01}{2.55}\right)^{2} \\
& =0.2255
\end{array}
$$

The partial volume of a head would be given by:

$$
\begin{gathered}
V_{p}=(2.54)^{3}(0.2255)\left(\frac{\pi}{12}\right)\left[3\left(\frac{0.762}{2.54}\right)^{2}-2\left(\frac{0.762}{2.54}\right)^{3}\right] \\
=0.20896 \mathrm{~m}^{3}
\end{gathered}
$$

Partial volume of the two heads $=0.41792 \mathrm{~m}^{3}$ Total volume $=0.41792+9.74=10.1579 \mathrm{~m}^{3}$

\subsection{Torispherical Head in Vertical Tank}

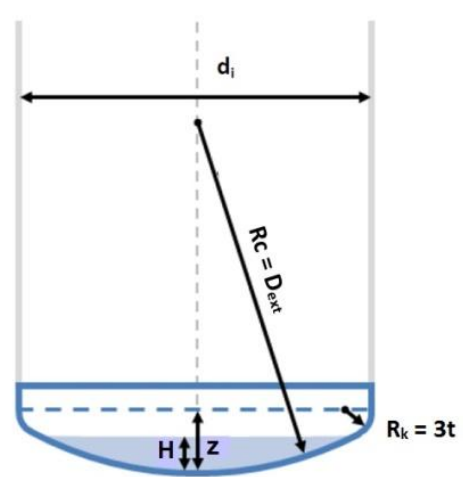

Fig 9. Vertical tank with torispherical head [10] 
Partial volume of liquid in the bottom head (12),

$V_{p}=\frac{\pi}{6}\left(\frac{3}{C} d_{i} H^{2}-\frac{2}{C^{2}} H^{3}\right)$

Partial volume at the upper head (13),

$V_{p}=\frac{\pi}{12}\left(3 d_{i}^{2} H-\frac{4}{C^{2}} H^{3}\right)$

The depth ( $\mathrm{z}$ ) of this type of heads is obtained with the equation (15):

$z=R_{c}-\sqrt{\left(R_{c}-R_{k}\right)^{2}-\left(\frac{D_{e x t}}{2}-t-R_{k}\right)^{2}}$

Where:

$$
t=\text { Thickness }
$$

$D_{\text {ext }}=$ External diameter $=d_{i}+t$

$R_{k}=$ Inside knuckle radius $=3 t$

$R c=$ Inside crown radius $=D_{\text {ext }}$

In addition, in accordance with the ASME code, the constant $\mathrm{C}$ is determined by (16):

$$
\begin{aligned}
C=0.30939+ & 1.7197\left(\frac{R_{k}-0.06 D_{\text {ext }}}{d_{i}}\right) \\
& -0.16116\left(\frac{t}{D_{\text {ext }}}\right)+0.98997\left(\frac{t}{D_{\text {ext }}}\right)^{2}
\end{aligned}
$$

And the total volume of the head is with the equation (17):

$V_{c}=0.9\left[\left(\frac{2 \pi R_{c}^{2}}{3}\right) z\right]$

\subsection{Total Volume of Torispherical Head or Cap. Calculation By Sections. [1]}

The following form of calculation can be applied to any profile with torispherical head. Unlike the general method shown earlier that an approximation of the total volume of the head, is obtained with the calculation by sections is achieved having the exact volume that occupies with torispherical head. Below is an outline of the head:

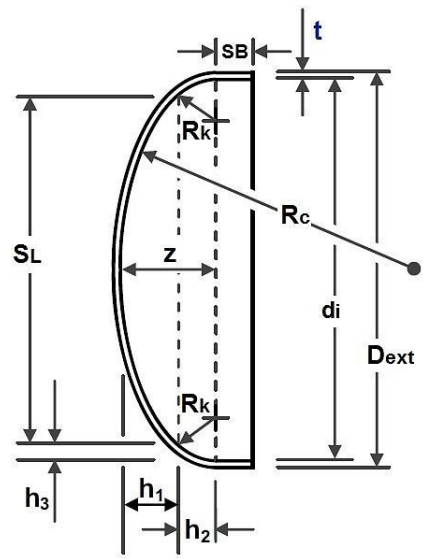

Fig 10. Sections with torispherical head [1]
As in the previous method, the depth $(\mathrm{z})$ is given by the equation (15):

$z=R_{c}-\sqrt{\left(R_{c}-R_{k}\right)^{2}-\left(\frac{D_{\text {ext }}}{2}-t-R_{k}\right)^{2}}$

Where:

$t=$ Thickness

$D_{\text {ext }}=$ External diameter $=d_{i}+t$

$R_{k}=$ Inside knuckle radius $=3 t$

$R c=$ Inside crown radius $=D_{\text {ext }}$

The spherical boundary $\left(\mathrm{S}_{\mathrm{L}}\right)$ is:

$S_{L}=R_{c}\left(\frac{d_{i}-2 R_{k}}{R_{c}-R_{k}}\right)$

While the height of the spherical section $\left(h_{1}\right)$ :

$h_{1}=R_{c}-\sqrt{R_{c}^{2}-\frac{S_{L}^{2}}{4}}$

Height of elliptical section $\left(h_{2}\right)$ :

$h_{2}=\sqrt{R_{k}^{2}-\left(\frac{S_{L}}{2}-\frac{d_{i}}{2}+R_{k}\right)^{2}}$

The difference between $\left(\mathrm{d}_{\mathrm{i}} / 2\right)$ and $\left(\mathrm{S}_{\mathrm{L}} / 2\right)$ is calculated as:

$h_{3}=\frac{R_{k}\left(R_{c}-\frac{d_{i}}{2}\right)}{R_{c}-R_{k}}$

To obtain the expression with which it is estimated the volume of the spherical section with torispherical head $\left(\mathrm{V}_{1}\right)$, is integrated from 0 to $h_{1}$, with respect to $d h$, the equation that defines the area of the cross-section of a spherical head:

$V_{1}=\pi \int_{0}^{h_{1}}\left(2 R_{c} h-h^{2}\right) d h$

$V_{1}=\pi\left(R_{c} h_{1}^{2}-\frac{1}{3} h_{1}^{3}\right)$

To obtain the expression which is calculated the volume of elliptical section with torispherical head $\left(\mathrm{V}_{2}\right)$, is integrated from 0 to $h_{2}$, with respect to $d h$, the equation that defines a portion of the area of the cross-section of an elliptical head:

$$
\begin{gathered}
V_{2}=\frac{\pi}{4} \int_{0}^{h_{2}}\left(d_{i}-2 R_{k}+2 \sqrt{R_{k}^{2}-h^{2}}\right)^{2} d h \\
V_{2}=\frac{\pi}{4}\left[8 R_{k}^{2} h_{2}-\frac{4}{3} h_{2}^{3}+2 d_{i} h_{2} \sqrt{R_{k}^{2}-h_{2}^{2}}+2 d_{i} R_{k}^{2}\right. \\
\cdot \arctan \left(\frac{h_{2}}{\sqrt{R_{k}^{2}-h_{2}^{2}}}\right)-4 R_{k} h_{2} \sqrt{R_{k}^{2}-h_{2}^{2}} \\
-4 R_{k}^{3} \cdot \arctan \left(\frac{h_{2}}{\sqrt{R_{k}^{2}-h_{2}^{2}}}\right)+d_{i}^{2} h_{2} \\
\left.-4 h_{2} d_{i} R_{k}\right] \quad(25)
\end{gathered}
$$

Finally, the total volume of with torispherical head is: 


$$
V_{c}=V_{1}+V_{2}
$$

Additional way, the exact value of $\mathrm{C}$, finds it is calculated as:

$$
C=\frac{12}{\pi}\left(\frac{V_{1}+V_{2}}{d_{i}^{3}}\right)
$$

\section{VOLUMES IN A CONICAL TANK} PARTIALLY FILLED

Conical tanks are less common in the chemical industry; they are rather used for grain storage. It is possible to find them so that the upper radius is smaller than the bottom or vice versa, as shown in the following figure:
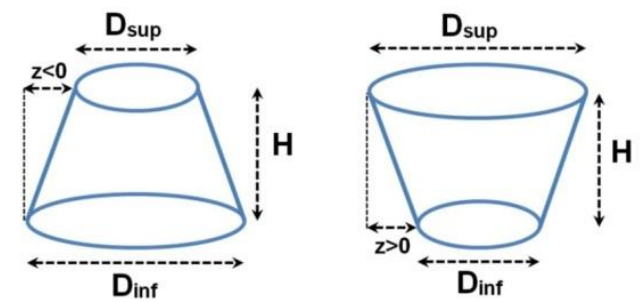

Fig 11. Conical tanks

Volume of liquid in the tank:

$V p=\frac{\pi}{12} H\left[\left(D_{\text {inf }}^{2}+D_{\text {inf }}\right) \times\left(D_{\text {sup }}^{2}+D_{\text {sup }}\right)\right]$

$Z=\frac{1}{2 H}\left(D_{\text {sup }}-D_{\text {inf }}\right)$

$z<0$ if $D_{\text {sup }}<D_{\text {inf }}$

$z>0$ if $D_{\text {sup }}>D_{\text {inf }}$

\section{Problem 5.}

What will be the volume contained in a conical tank with bottom diameter of $2 \mathrm{~m}$, a top diameter of $1 \mathrm{~m}$ and a height of liquid from $1.5 \mathrm{~m}$ ?

According to the data:

$z=\frac{1}{2 \times 1.5}(1-2)=-0.333$

The partial volume would be:

$V_{p}=\frac{\pi}{12}(1.5)[(4+2) \times(1+1)]=2.749 \mathrm{~m}^{3}$

\section{VOLUME IN A PARTIALLY FLUID-FILLED}

\section{SPHERE}

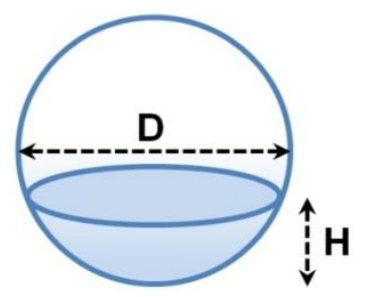

Fig 12. Sphere
Total volume of the sphere $=\frac{4}{3} \pi R^{3}=\frac{1}{6} \pi D^{3}$

Partial volume $=\frac{\pi}{3} H^{2}(1.5 D-H)$

\section{Problem 6.}

A tank in the shape of a sphere of $2.5 \mathrm{~m}$ internal diameter is filled to a height of $0.5 \mathrm{~m}$ with liquid. What is the volume of liquid contained in the sphere?

Total volume $=\frac{1}{6} \pi(2.5)^{2}=3.725 \mathrm{~m}^{3}$

Partial volume $=\frac{\pi}{3}(0.5)^{2}[(1.5 \times 2.5)-0.5]$

$$
=0.8508 \mathrm{~m}^{3}
$$

The tank is filled in a $22.8 \%$.

\section{CONCLUSIONS}

Obtaining the volume contained in a tank is not simple, since it depends on the geometry of the tank, its position and if the tank is full or not. An additional complication arises from the fact that many tanks have caps or heads in different shapes. As you can see, heads volumes must be calculated separately and add to the volume of the cylindrical portion of the tank. The four types of heads that are used most frequently are the head standard concave, ASME head or torispherical, the ellipsoid and the hemispherical.

\section{REFERENCES}

[1] Wiencke Bent. Computing the partial volume of pressure vessels. International journal of refrigeration (33): 868-876, 2010.

[2] Perry - Manual of the Chemical engineers - McGraw Hill - Mexico - 2001

[3] Valiente Barderas Antonio - Problemas de flujo de fluidos - Limusa - Mexico-2006.

[4] Aqua Dyn Tankvolumecalculator-http: www.aquadyntech.com/tanksvolume.html

[5] Dubois'sTank calculador:http://www.duboisi.com/tankcalc.htm

[6] Storage Tank volume Calculations-http: www.arachnoid.com/tank_volume/

[7] Tank calculations:http:orbitindustries.com/pages/api\%20tank s/tkcalc.htm

[8] Tank levels \& volumes. http://www.ghsport.com/tank.htm

[9] Volume and wetted area of partially filled horizontal vessels: https://neutrium.net/equipment/volume-andwetted-area-of-partially-filled-vessels/

[10] Volume and wetted area of partially filled vertical vessels: https://neutrium.net/equipment/volume-andwetted-area-of-partially-filled-vertical-vessels/ 